\title{
Difference between the biologic and chronologic age as an individualized indicator for the skin care intensity selection: skin topography and immune system state studies, parameter correlations with age difference
}

Yurij Sukhovei ${ }^{1}$, Elena Kostolomova ${ }^{1}$, Irina Unger ${ }^{1}$, Andrey Koptyug ${ }^{2^{*}}$ (D) and Denis Kaigorodov ${ }^{1}$

\begin{abstract}
Background: Present research addresses the issue of skin aging and corresponding skin treatment individualization. Particular research question was on the developing of simplified criterion supporting patient-specific decision on the necessity and intensity of skin treatment. Basing on the published results and a wide pool of experimental data, we have formulated a hypothesis that a difference between biologic and chronologic age can be used as an express criterion of skin aging.

Methods: In present paper, we report the results of studies with 80 volunteers between 15 and 65 years of age, linking parameters reflecting immune state, skin state, and topography to the difference between biologic and chronologic age. Facial skin topography, skin moisture, sebum level, and skin elasticity were studied using commercial devices. Blood immunology studies were performed using venous blood samples. Correlations between all measured parameters and age difference were calculated. Also, cross correlations between skin cell profile and blood immune profile parameters, and skin roughness parameters were calculated.

Results: Age dependencies of the blood immunological parameters on the biologic and chronologic age difference are less pronounced as compared to the changes in skin cell profile parameters. However, the changes in the tendencies when biologic age becomes equal to chronologic one are visible for all studied parameters. All measured skin roughness parameters show correlations with age difference, but average skin roughness and depth of the deepest profile valley have the largest correlation coefficient values. Many of the measured skin cell profile and blood immunology parameters show strong correlations with average skin roughness and deepest profile valley, with some of the coefficients exceeding 0.5-0.6.

Conclusions: Basing on own experiments and published research results, it is possible to suggest using the difference between calculated biologic age and chronologic age as an individualized criterion supporting decisions on skin treatment strategy. Further research involving larger numbers of participants and aiming on optimizing the expressions for calculating biologic age could lead to reliable and easily available express criterion supporting the decision making for an individualized skin treatment.
\end{abstract}

Keywords: Skin aging, Biologic and chronologic age, Skin topography, Immune status, Individualized treatment

\footnotetext{
* Correspondence: andrey.koptyug@miun.se

${ }^{2}$ Mid Sweden University, SportsTech Research Centre, Akademigatan 1,

Östersund, Sweden

Full list of author information is available at the end of the article
}

(c) The Author(s). 2020 Open Access This article is distributed under the terms of the Creative Commons Attribution 4.0 International License (http://creativecommons.org/licenses/by/4.0/), which permits unrestricted use, distribution, and reproduction in any medium, provided you give appropriate credit to the original author(s) and the source, provide a link to the Creative Commons license, and indicate if changes were made. The Creative Commons Public Domain Dedication waiver (http://creativecommons.org/publicdomain/zero/1.0/) applies to the data made available in this article, unless otherwise stated. 


\section{Introduction}

Addressing of the issue on proper and timely measures against human skin aging is a complex problem for cosmetology and medicine involving among others physiological, social, and psychological aspects (Waters 1986; Koblenzer 1996; Gilchrest 2003; Gupta and Gupta 2003; Gupta and Gilchrest 2005; Matts 2008; Bhomick and Rao 2014; Konduracka et al. 2014; Zhang and Duan 2018). Low self-perception of skin quality is often forcing people to seek intense intervention, which may be not necessary or even harmful (Waters 1986; Bhomick and Rao 2014; Konduracka et al. 2014). Multiple studies have suggested objectively measurable skin properties and biochemical parameters (markers) that can be used for assessing if the skin is aging and needs certain cosmetic or medical intervention (Kwon and da Vitoria Lobo 1999; Jacobi et al. 2004; Klemera and Doubal 2006; Gruenewald et al. 2006; Naylor et al. 2011; Mann et al. 2012; Arce-Lopera et al. 2013; Porcheron et al. 2013; Freis and Perie 2014; Masuda et al. 2014; Shetage et al. 2014; Woo et al. 2014; Belsky et al. 2015; Trojahn et al. 2015; Belsky et al. 2017). Corresponding methodologies cover the analysis of skin images (e.g., Matts 2008; Kwon and da Vitoria Lobo 1999; Arce-Lopera et al. 2013), skin topography (e.g., Jacobi et al. 2004; Masuda et al. 2014; Shetage et al. 2014; Trojahn et al. 2015) and mechanical properties (e.g., Porcheron et al. 2013; Freis et al. 2014; Woo et al. 2014), skin biochemistry (e.g. Naylor et al. 2011; Mann et al. 2012), etc. So far, it is accepted that multiparameter (multimarker)-based methods are the best candidates for the development of aging criteria, in particular the criteria of skin aging (e.g., Voitenko and Tokar 1983; Alonso-Fernández and de la Fuente 2011; Castelo-Branco and Soveral 2014; Martínez de Toda et al. 2016; Kang et al. 2017; Csaba 2019; Fahy et al. 2019). Recent research makes use of an old concept of biologic age (Benjamin 1947), suggesting introduction of a cumulative factor including multiple parameters related to aging process (e.g., Voitenko and Tokar 1983; Klemera and Doubal 2006; Gruenewald et al. 2006; Alonso-Fernández and de la Fuente 2011; CasteloBranco and Soveral 2014; Belsky et al. 2015; Belsky et al. 2017; Martínez de Toda et al. 2016; Kang et al. 2017; Csaba 2019; Fahy et al. 2019). Modern approach to the calculation of biologic age (BA) incorporates a number of objectively measurable and quantifiable parameters including body mass index, arterial pressure, different cardiorespiratory parameters, blood cholesterol levels and white blood cell counts, urea composition, etc. (e.g., Voitenko and Tokar 1983; Klemera and Doubal 2006; Gruenewald et al. 2006; Alonso-Fernández and de la Fuente 2011; Castelo-Branco and Soveral 2014; Martínez de Toda et al. 2016; Kang et al. 2017; Csaba 2019; Fahy et al. 2019). These parameters are used in formal mathematical expressions for calculating estimated BA value. Different researchers utilize different sets of parameters and different expressions, but one can outline few common conclusions. Firstly, in the groups of individuals with the same chronologic age (CA; age according to the year of birth), biologic age is covering the values from far lower to far higher than the chronologic age (Voitenko and Tokar 1983; Alonso-Fernández and de la Fuente 2011; Castelo-Branco and Soveral 2014; Belsky et al. 2015; Trojahn et al. 2015; Belsky et al. 2017; Martínez de Toda et al. 2016; Kang et al. 2017; Csaba 2019; Fahy et al. 2019). Basing on a study of calculated biologic age for individuals with the same chronologic age and significant difference of $\mathrm{BA}$ and $\mathrm{CA}$, it was found that a pace of aging is increasing with increasing chronologic age. Our studies indicate that there is a noticeable and measurable difference in many parameters reflecting the state of human skin for the individuals with BA < CA and BA > CA (Sukhovei et al. 2019).

Basing on available information, a hypothesis was formulated that a difference between the chronologic and biologic age can be used as an express indicator of skin aging. If such hypothesis is supported, it would open a pathway for developing an express criterion supporting decisions on an individualized skin treatment. In addition, it was concluded that corresponding biologic age value could be calculated using a simplified approach demanding only basic parameters that could be acquired from tests performed ambulatory or in almost every clinic. Discussed results of experimental studies on dependencies of the parameters reflecting skin state (cellular structure) and their correlations with the biologic and chronologic age difference (BA - CA) provided certain grounds for the validity of such hypothesis (Sukhovei et al. 2019). Basing on the available data, it was concluded that for stated purposes gender-specific expressions for calculating biologic age should be used. Literature studies also indicate that for chosen specific purpose of designing express criterion for the individualized skin treatment different approaches for BA calculation may be equally useful. Further studies are needed to understand if such approach is universal and does not strongly depend on the choice of particular expression of BA calculation, or certain specific formula is most relevant.

In the present paper, we continue the discussion of formulated hypothesis describing the studies of parameters reflecting skin state (moisture, elasticity, and sebum level), skin topography, cellular structure, and overall body immune status of the study participants. Immune studies were added to the overall research scope reflecting the importance of the immune status changes in the aging process (Voitenko and Tokar 1983; Kiecolt-Glaser et al. 2003; Alonso-Fernández and de la Fuente 2011; 
Castelo-Branco and Soveral 2014; Martínez de Toda et al. 2016; Kang et al. 2017; Csaba 2019; Fahy et al. 2019).

\section{Materials and methods}

Studies were carried out with a group of volunteers between 15 and 65 years of chronologic age (40 males and 40 females) recruited predominantly from the city population. There was no pre-selection of the participants depending on the health or their skin state. Participants were thoroughly informed on the purpose of the studies and procedures involved and gave their written consent. The plans for the research and consent forms were approved by the Ethics Commission of the Institute of Immunology (IRB 1025402458740) according to the formal documents issued by the State Department of Health of Russian Federation. All procedures were conducted by the qualified personnel in accordance with principles of the Declaration of Helsinki and its amendments (World Medical Association Declaration of Helsinki 2013). The average age of the male and female participants was $39.05 \pm 2.28$ and $39.48 \pm 2.28$ years, correspondingly.

\section{Calculation of the biologic age}

The following expressions for the biologic age calculations were used:

$$
\text { for females } \begin{aligned}
B A= & 51.01+0.84^{*} U C-5.53^{*} F V C \\
& +0.2^{*} S B P \\
& +0.093^{*} B C h-5.53^{*} B C a
\end{aligned}
$$

$$
\text { for male } \begin{aligned}
B A= & 93.86+0.44^{*} U C-4.92^{*} F V C \\
& +0.19^{*} S B P \\
& +0.10^{*} B C h-9.01^{*} B C a
\end{aligned}
$$

where $F V C$ is the forced vital lung capacity (liter) measured using common medical spirometer, $S B P$ is systolic blood pressure $(\mathrm{mm} \mathrm{Hg})$ measured by a cuff tonometer, $U C$ is urea concentration in urine $(\mathrm{mg} / 100 \mathrm{ml})$, and $B C h$ is a blood cholesterol level $(\mathrm{mg} / 100 \mathrm{ml})$ and $B C a$ is a calcium level $(\mathrm{mg} / 100 \mathrm{ml})$ in the blood serum. Corresponding expressions for BA calculations are common for gerontology and age-related studies in Russia (Voitenko and Tokar 1983; Beloserova 2006; Sukhovei et al. 2019). Note that these expressions give overestimated values of BA for early age and underestimated for late age, compared to the corresponding expressions used by other researchers underestimating BA in early age and overestimating it at late age (Webster and Logie 1976; Dean 1986; Borkan and Norris 1980; Dean 1998). In addition, with the approach to BA calculations used in the present research, young age is corresponding to BA > CA, which may be some counterintuitive but does not influence the purpose of present study.
Biologic age was calculated for each of the participants according to expressions (1) and (2). According to the formulated hypothesis, one should be able to select the individuals that "should not need skin corrective intervention" and "may require intensive corrective intervention." Following this approach, we have identified three sub-groups for each sex corresponding to "early age," "critical age," and "late age" as reflected by the age difference BA - CA (Sukhovei et al. 2019). A group for "critical age" was defined as having this difference less than 5 years:

$$
|\mathrm{BA}-\mathrm{CA}|<5 \text { years }
$$

Thus, three sub-groups were chosen to have chronologic age below and above the "critical" (BA is clearly larger or clearly smaller than $\mathrm{CA}$ ) and around the "crossover" age (BA CA). Individual scatter of the values in BA vs CA dependences is rather significant, so basing on all experimental data acquired we have adopted a simplified approach to the "critical age" sub-group selection linked to the biologic age but basing on the chronologic one. So finally, the conditions for the three sub-group selection were chosen as follows: below 40 , between 40 and 50 , and above 50 years for the male subjects; and below 30, between 30 and 40, and above 40 years for the female subjects.

Thus, the definition of the simplified criteria for the age sub-group selection is:

$$
\begin{aligned}
& \text { critical chronologic age group, male } \\
& \text { - between } 40 \text { and } 50 \text { years; } \\
& \text { critical chronologic age group, female } \\
& \text { - between } 30 \text { and } 40 \text { years; }
\end{aligned}
$$

Further, we refer to these groups as "early age," "critical age," and "late age" ones.

\section{Assessment of the skin topography}

Skin topography was measured using optical PRIMOS 3D scanner (by GF Messetechnik, Germany) on the face of the participants according to the protocol defined by the manufacturer. The following parameters of the skin topography were extracted using the embedded algorithms within PRIMOS system:

- Average roughness, $S a$

- Maximum stretching of the roughness profile, Smax (difference between the highest "peak" and the deepest "valley" within the whole measured area)

- Ten-point height, $S z$ (average value of 5 highest peaks minus average value of five deepest valleys within the whole measured area)

- Height of the greatest profile peak, $S p$

- Depth of the deepest profile valley, $S v$ 
- Arithmetic mean of the profile slope of the roughness profile, $S d a$

\section{Assessment of the skin state}

The following parameters were measured to assess the state of the facial skin:

- Skin moisture-by the Corneometer (Courage \& Khazaka GmbH, Germany)

- Sebum level of the skin surface-by Sebumeter ${ }^{\circ}$ SM 815 (by Courage \& Khazaka electronic $\mathrm{GmbH}$, Germany).

- Elasticity of the upper skin layer-by Cutometer 580 MPA (by Courage \& Khazaka electronic $\mathrm{GmbH}$, Germany).

Cutometer uses mild negative pressure that deforms the skin mechanically to measure skin displacement with the pressure. Corresponding skin elasticity parameters (R-parameters) are extracted using the embedded software. Corresponding values measured for all participants were close to the values for the corresponding age groups reported in the literature (Nedelec et al. 2016; Coltman et al. 2017).

\section{Assessment of the immune system state}

Blood immunology tests were conducted to assess the general health status of the participants. The following factors were chosen for the analysis:

- Erythrocyte count (RBC)

- Leukocyte common antigen (CD45)

- T lymphocytes (CD45+CD3+) and their subpopulations

- Th lymphocytes or T-helpers (CD45+CD3+CD4+CD8-)

- Cytotoxic Ts lymphocytes (CD45+CD3+CD4 $-\mathrm{CD} 8+)$

- B lymphocytes (CD45+CD3-CD19+)

- Natural Killer (NK) cells (CD45+CD3 -CD16+CD56+)

- Immunologic index (CD45+CD3+CD4+/ $\mathrm{CD} 45+\mathrm{CD} 3+\mathrm{CD} 8+)$

- Immunoglobulin concentration in the blood serum (IgA, IgG, IgM, IgE)

- Blood macrophage and microphage activity

Blood immunology was studied using venous blood samples taken using BD Vacutainer system (by Bioline, USA). Functional lymphocyte analysis was performed for untreated blood using indirect immunofluorescence with Cytomics FC500 Flow Cytometry Analyzer (Beckman Coulte Inc., USA) using monoclonal antibodies CYTOSTAT tetraCHROME CD45-FITC/CD4-RD1/CD8-ECD/
CD3-PC5 and CYTO-STAT tetraCHROME CD45FITC/CD56-RD1/CD19-ECD/CD3-PC5 (by Beckman Coulte Inc., USA). Erythrocyte samples for flow cytometry were prepared using COULTER Q-PREP Workstation and reagent system COULTER IMMUNOPREP (both by Beckman Coulte Inc., USA) according to the protocols specified by the equipment manufacturer.

Skin-resident macrophage concentration and activity were measured using the same biopsy samples as used for the skin cell studies under flow cytometry according to common protocols. Blood monocyte count was measured using sample-stained glass in optical microscope. Metabolic blood monocyte activity was assessed using spontaneous and stimulated nitro-blue tetrazolium test (NBT; Freeman and King 1972; Gordon et al. 1973; Müller et al. 1981; Hart et al. 1999; Mosser and Zhang 2011; Kazanci et al. 2017). Blood monocyte phagocytic activity was assessed through the expression of $\mathrm{Fc} \gamma \mathrm{RIII}\left(\mathrm{Fc}^{\gamma}\right.$ receptor III, CD16) using the ingestion and attachment of the opsonized sheep erythrocytes (Mosser and Zhang 2011). Quantization of the phagocytosis of opsonized sheep erythrocytes by macrophages was done visually under optical microscope by measuring the numbers of monocytes attached to the membrane surface of opsonized sheep erythrocytes (membrane-bound monocytes) and the number of monocytes that have ingested opsonized sheep erythrocytes (monocyte-ingested erythrocytes), as a percentage of the overall monocyte numbers. Mastocyte count measurement was incorporated into the experimental procedure as their levels were shown to decrease with aging in animal experiments (Benjamin 1947; Voitenko and Tokar 1983; Hart et al. 1999; Martínez de Toda et al. 2016; Kang et al. 2017; Csaba 2019; Fahy et al. 2019).

Concentrations of blood immunoglobulins were measured by turbidimetry using Modular Pre-Analytics EVO analyzer with the immunochemical module E140 (Roche, Switzerland) with the test system for nephelometry and turbidimetry by Dako, USA. Quantization of soluble immune complexes was done using precipitation by polyethyleneglycol (PEG; Chia et al. 1979; Ohlson and Zetterstrand 1985; Giaimis et al. 1992) using two different PEG concentrations (3.5 and 7 vol. \%).

Phagocytic activity of the blood and epidermal neutrophils was assessed using adhering/ingestion method with Saccharomyces cerevisiae (brewer's yeast, Giaimis et al. 1992). The following parameters were recorded: percentage of active neutrophils participating in active phagocytosis and phagocytosis intensity as the mean number of adhered/ingested cells per phagocytizing neutrophil after 30 and $120 \mathrm{~min}$ from the start of experiment.

\section{Statistical analysis}

Pearson statistical and correlation analysis was carried out using the software package IBM SPSS Statistics Base 
v 22.0. Though the data sample size is not large enough to suggest adequate statistical analysis, one can already formulate certain preliminary conclusions.

\section{Results}

A large pool of experimental data was acquired and analyzed in the study. Here, we report on the data analysis and the most representative results for the parameters reflecting skin state and roughness, and blood immune status followed by the discussion on correlations of studied parameters with age difference BA - CA, and correlations of the skin roughness parameters with other measured skin and blood immunology status parameters. The age dependencies of the skin cell profile parameters were analyzed in a previous paper (Sukhovei et al. 2019), and it was concluded that plotting the values against the difference between biologic and chronologic age allows to clarify certain tendencies and illustrate the trend changes around $\mathrm{BA}=\mathrm{CA}$. Thus, it was of significant interest to analyze if similar tendencies will be present for the blood immunology and skin roughness parameters.

\section{Immune system status changes with the age difference $B A-C A$}

It was already shown that skin cell profile parameters often show certain interesting features when plotted against the age difference $\mathrm{BA}=\mathrm{CA}$ and are quite monotonous when plotted against either chronologic or biologic age. In addition, it was noted that in some cases plotting such dependencies against the normalized age difference makes specific features more clear. Similar data processing was used for the analysis of the blood immunology profile parameters (Figs. 1 and 2). Although acquired data have significant scatter, certain hints toward the special case of $\mathrm{BA}=\mathrm{CA}$ already can be observed. It should be noted that plotting the dependencies against age difference (BA $\mathrm{CA}$, as in Fig. 2a), or normalized age difference (for example, (BA - CA)/BA, as in Fig. 2b) does not change the general trends as compared to the plot against age difference BA - CA.

In order to validate that age difference $\mathrm{BA}=\mathrm{CA}$ can be used as a simplified criterion of aging, corresponding dependencies are visualized with the cumulative data averaged for the age sub-groups corresponding to "early," "critical," and "late" chronologic age (expressions 4 and 5), similarly to the approach used previously (Sukhovei et al. 2019). As the scatter of the values in the plots against age difference is rather significant between participants, this sub-group age breakdown selection was done basing on the full set of obtained experimental data.

Bar plots in Fig. 3 present averaged levels of blood immunoglobulins for the chosen age sub-groups. Three left bars in each plot correspond to female, three right bars to male participants. Though some of the trends are less pronounced, there is certain tendency to have trend changes around $(\mathrm{BA}=\mathrm{CA}) \pm 5$ years.

Previous studies reported contradicting trends in the immunoglobulin concentration changes. It is assumed that among the main reasons for that are the differences in the age and gender of test subjects, location of the immune cells, and study methods (Voitenko and Tokar 1983; Alonso-Fernández and de la Fuente 2011; CasteloBranco and Soveral 2014; Martínez de Toda et al. 2016; Kang et al. 2017; Csaba 2019; Fahy et al. 2019). There are reports that the levels of IgA in saliva are increasing up to about 60 years of age followed by the decline (Castelo-Branco and Soveral 2014), which is quite similar to the trends shown in Fig. 3a. For the purpose of our research, dependencies of the blood immunoglobulin concentrations can still be used as certain argument for the formulated hypothesis.

Bar plots in Fig. 4 present averaged values reflecting the metabolic monocyte activity in spontaneous (a) and stimulated (b) NBT Test, and the phagocytic activity of the monocytes (percentage of membrane-bound monocytes $(\mathbf{c})$ and of monocyte-ingested erythrocytes $(\mathbf{d}))$ in

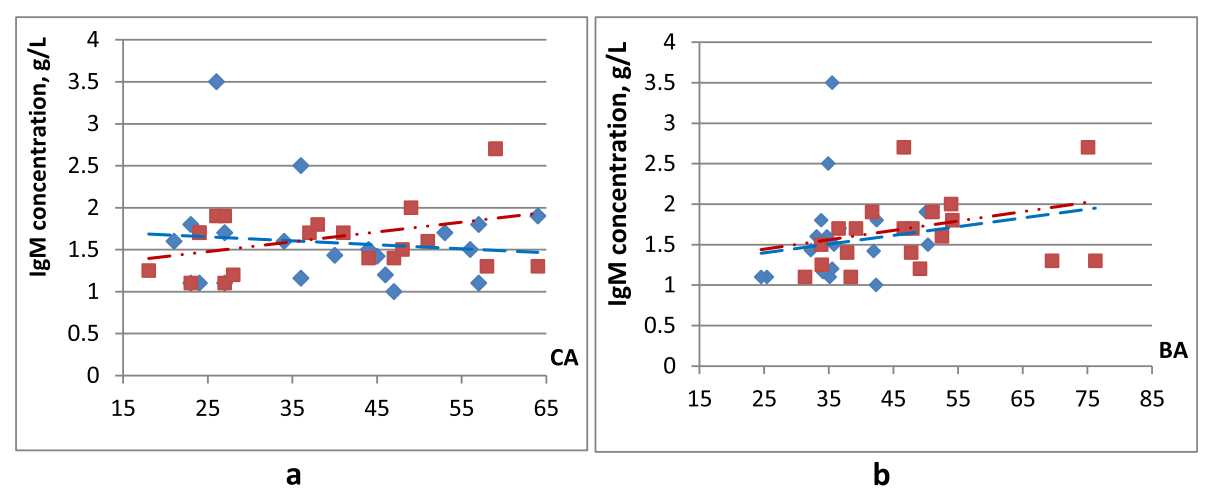

Fig. 1 Changes in the blood concentrations of immunoglobulin M plotted against the chronologic (a) and biologic (b) age. Squares (linear fit: double-dotted line) — male participants; diamonds (linear fit: dashed line)—female participants. Trend lines (a): female $y=0.011 x+1.185, R^{2}=$ 0.138; male $y=-0.004 x+1.770, R^{2}=0.012$. Trend lines $(\mathbf{b})$ : female $y=0.010 x+1.127, R^{2}=0.097$; male $y=0.011 x+1.156, R^{2}=0.018$ 

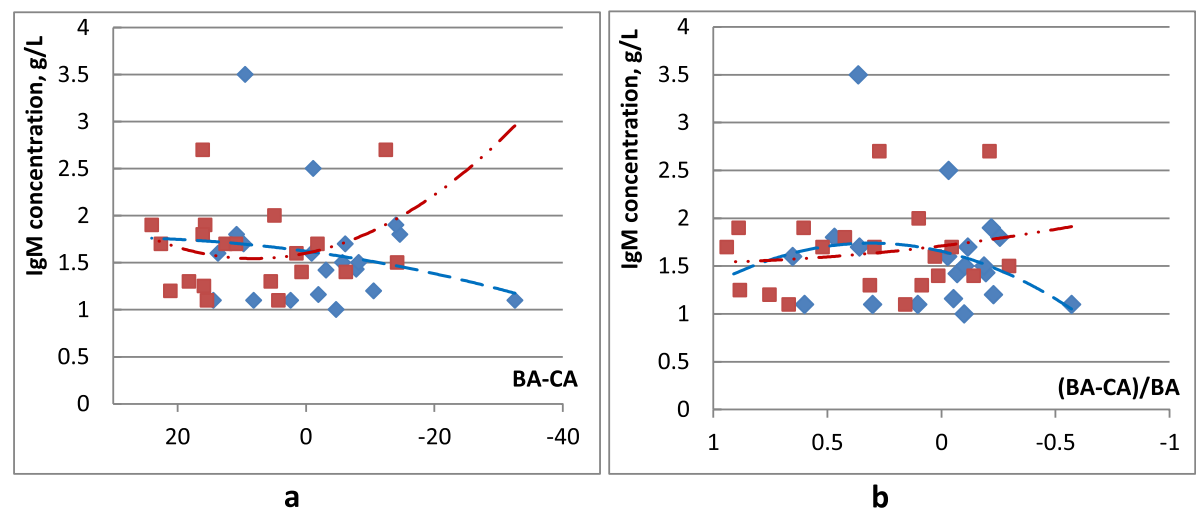

Fig. 2 Changes in the blood concentration of immunoglobulin M plotted against a biologic and chronologic age difference BA - CA, and normalized age difference (BA - CA)/BA. Squares (second order polynomial fit: double-dotted line) —male participants; diamonds (second order polynomial fit: dotted line)—female participants. Note that large positive difference BA - CA corresponds to early age. Trend lines (a): female $y=$ $0.0009 x^{2}-0.0139 x+1.6008, R^{2}=0.0680 ;$ male $y=-0.0001 x^{2}+0.0091 x+1.6232, R^{2}=0.0471$. Trend lines (b): female $y=-0.890 x^{2}+0.549 x+$ $1.654, R^{2}=0.069 ;$ male $y=-0.890 x^{2}+0.549 x+1.654, R^{2}=0.069$

the opsonization tests for the chosen age sub-groups. Three left bars in each plot correspond to female, three right bars to male participants. Certain tendency to have trend changes around $((\mathrm{BA}=\mathrm{CA}) \pm 5$ years $)$ is also pronounced.

Plots in Fig. 5 present the levels of phagocytic activity and intensity of phagocytosis of blood neutrophils 30 and $120 \mathrm{~min}$ of the test for the chosen age sub-groups. Again, trend changes are visible around $(\mathrm{BA}=\mathrm{CA}) \pm 5$ years.

Previous studies generally report on the decreasing with age overall numbers of monocytes and NK cells and greater adherence of neutrophils (Alonso-Fernández and de la Fuente 2011). In general, researchers pay more attention towards the changes in the functioning of the innate immunity cells with age (Voitenko and Tokar 1983; Alonso-Fernández and de la Fuente 2011; CasteloBranco and Soveral 2014; Martínez de Toda et al. 2016; Kang et al. 2017; Csaba 2019; Fahy et al. 2019). However, as it is with the changes in the immunoglobulin concentrations, changes in the corresponding trends of the age dependencies of the innate immunity cells can be used in support of the formulated hypotheses.

\section{Skin state and topography changes with the age difference BA - CA}

Measured skin moisture, elasticity, and sebum level values are in general agreement with previously reported

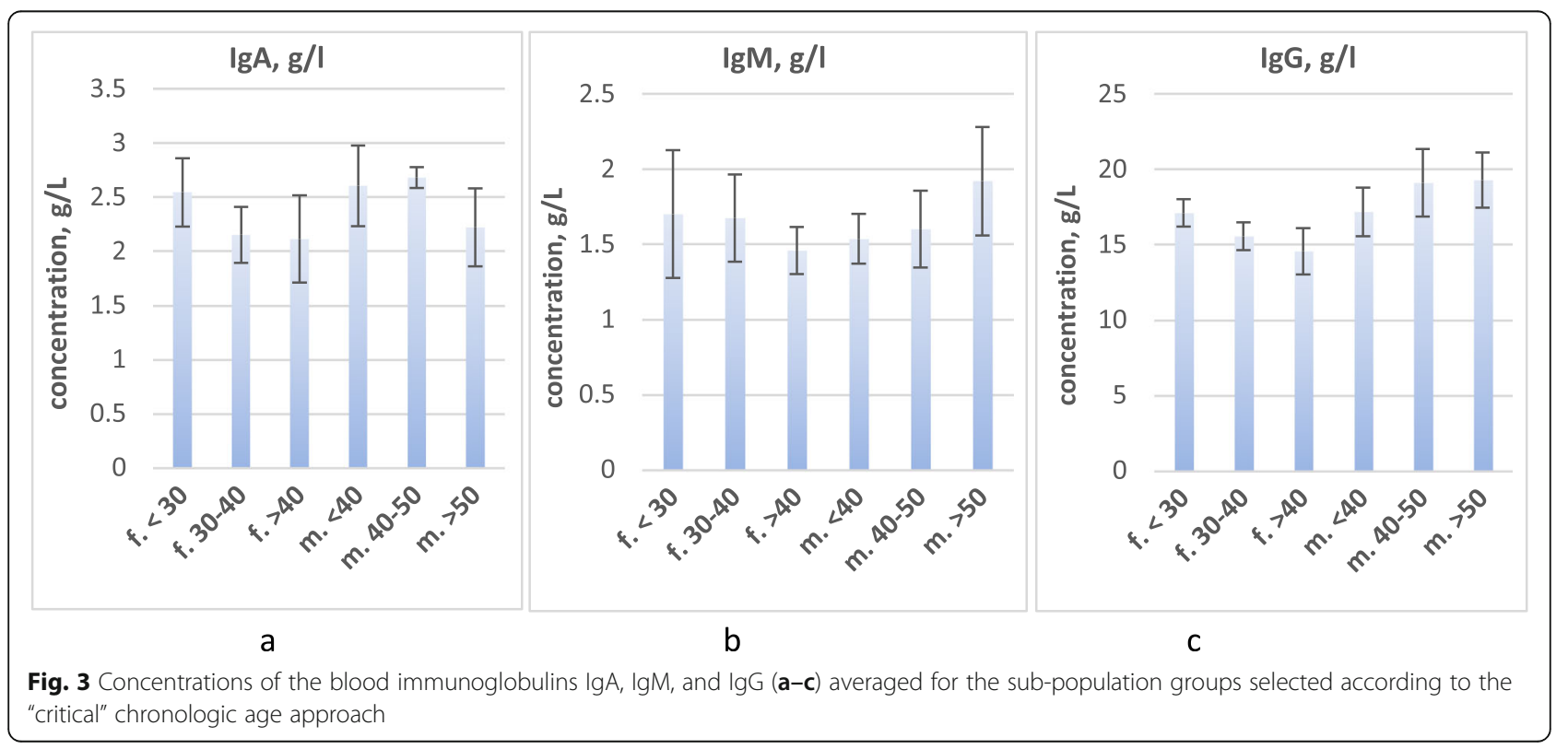




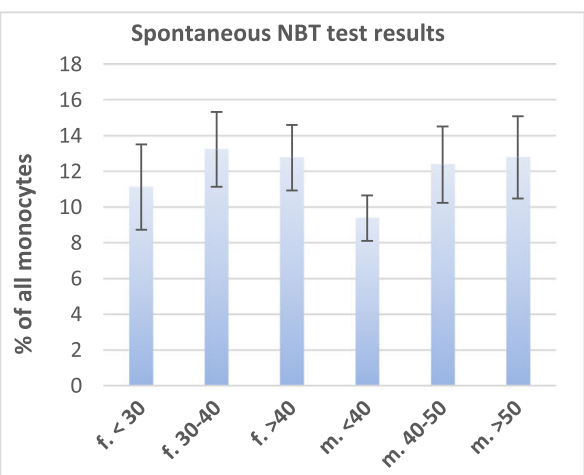

a

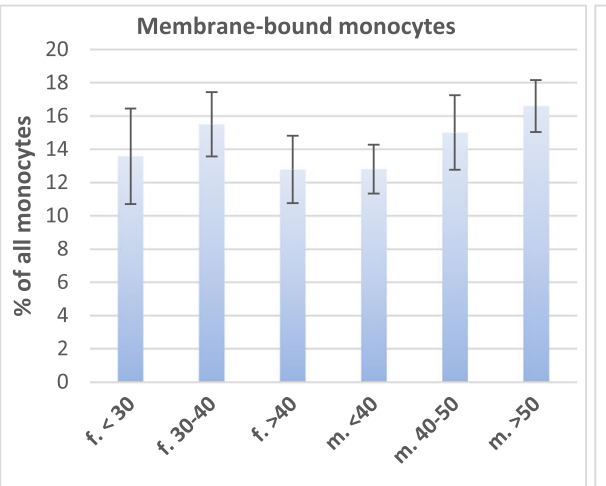

c

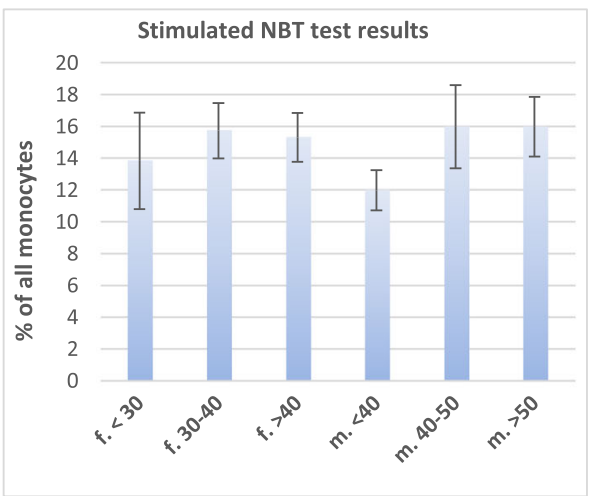

b

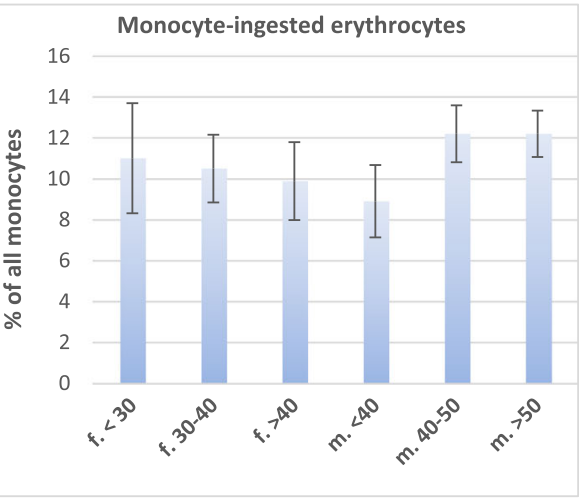

d

Fig. 4 Functional activity of the blood monocytes for the sub-population groups selected according to the "critical" chronologic age approach. Results of spontaneous (a) and stimulated (b) NBT tests. Percentage of the membrane-bound monocytes (c) and monocyte-ingested erythrocytes (d), relative to the overall monocyte numbers

data (Castelo-Branco and Soveral 2014). Nevertheless, as corresponding age dependence plots for these values have quite a large scatter, they cannot be used for supporting or opposing the formulated hypotheses. Data from the skin roughness measurements by the Cutometer are used for arguing and in general are in good agreement with previously reported values (Nedelec et al. 2016; Coltman et al. 2017).

Initially, the parameter values were plotted against the difference between the biologic and chronologic age (BA - CA). However, it became clear that corresponding trends are becoming more pronounced if the data are plotted against "normalized age difference" (BA - CA)/ $\mathrm{CA}$, similar to the case for the parameters reflecting skin cell profile and blood immunology status. Large number of parameters calculated by the Cutometer show similar trends, and plots for average roughness $(\mathrm{Sa})$ and maximum span of the roughness profile (Smax, difference between the highest "peak" and the deepest "valley" within the complete measured area) are presented in Fig. 6 as an example. Other measured roughness parameters have similar dependences on the age difference. Note that positive normalized age difference $(\mathrm{BA}-\mathrm{CA}) / \mathrm{CA}$ corresponds to early age, negative difference to late age participants. It should be also pointed out that corresponding dependencies on the normalized age "soften" the tendency towards increasing of skin roughness for BA $<$ CA (late age).

Similar shift in the same direction was observed for the female participants, which indicates that certain corrections into the expressions for the calculating of biologic age may be needed. Best data fit for the experimental dependencies in Fig. 6 was achieved using the exponential trend lines; corresponding expressions are given in Table 1.

It can be noticed that the scatter in the skin roughness values presented in Fig. 6 also seems to depend on the normalized age difference. Figure 7 presents some examples for the dependencies of the modulus of the difference between the measured values and trend lines shown in Fig. 6 (expressions for the trend lines are according to Table 1) on the normalized age difference $(\mathrm{BA}-\mathrm{CA}) / \mathrm{CA}$.

\section{Discussion}

Age dependencies of the chosen parameters for individual subjects show significant scatter of the values. Also, 


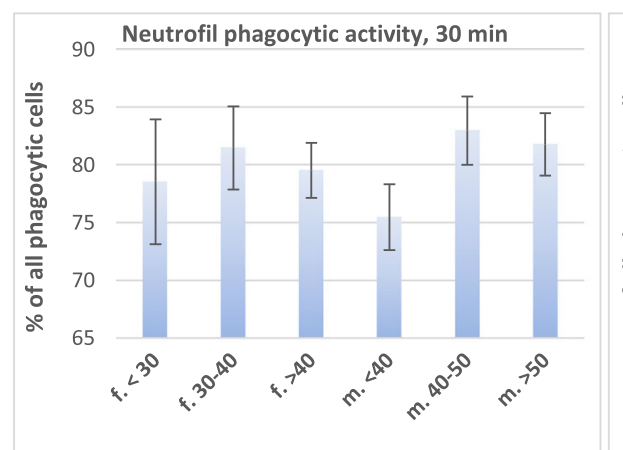

a

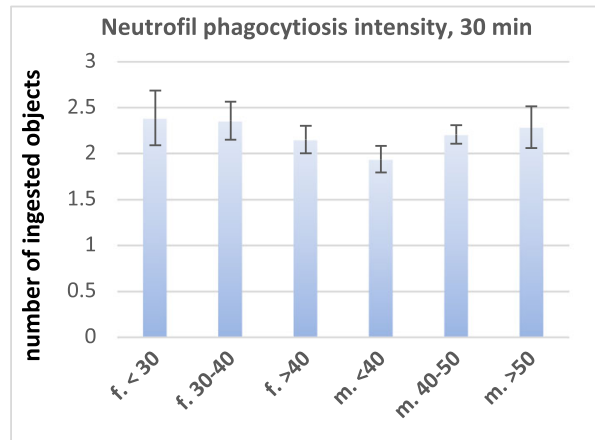

C

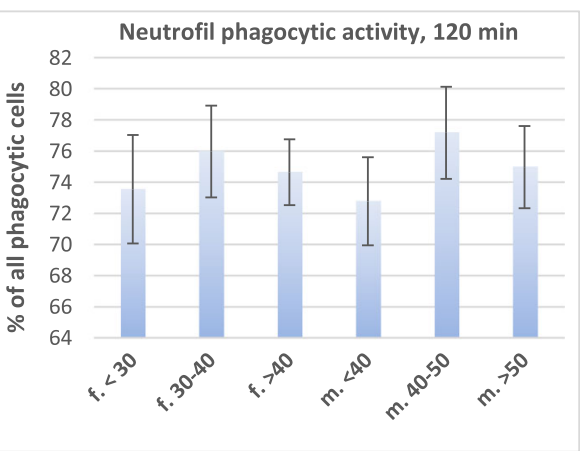

b

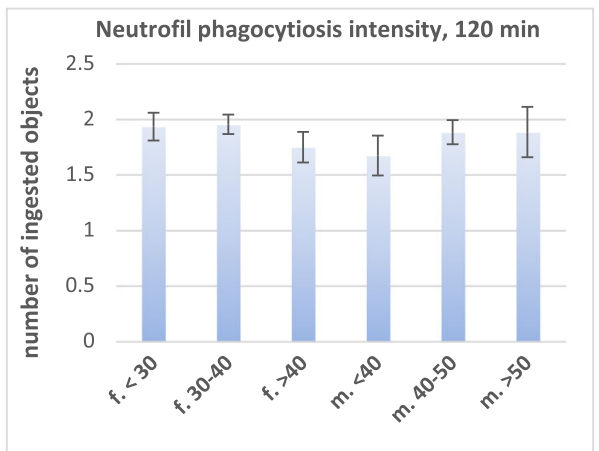

d

Fig. 5 Phagocytic activity of blood neutrophils after 30 (a) and 120 (b) minutes of the test and intensity of phagocytosis of blood neutrophils after 30 (c) and 120 (d) minutes of the test

the dependencies of the parameters reflecting blood immunology status and skin roughness on either biologic or chronologic age (Figs. 1 and 2) do not show the trend changes around $\mathrm{BA}=\mathrm{CA}$. As in the case for the parameters reflecting skin cell profile (Sukhovei et al. 2019), analysis of the parameter plots against age difference or normalized age difference suggests that skin aging selection criterion basing on the comparison of the biologic and chronologic age has certain grounds. In the data averaged for chosen age sub-groups ("early age," "critical age," "late age," reflecting the individual differences between chronologic and calculated biologic age BA CA) interesting trends are also visible, although the interval corresponding to "critical" age is chosen to be reasonably large $(\mathrm{BA}=\mathrm{CA} \pm 5$ years) and its boundaries are chosen rather arbitrary. Firstly, there is a clear difference in the "critical age" condition $(\mathrm{BA}=\mathrm{CA})$ for male and female participants. Corresponding value trends

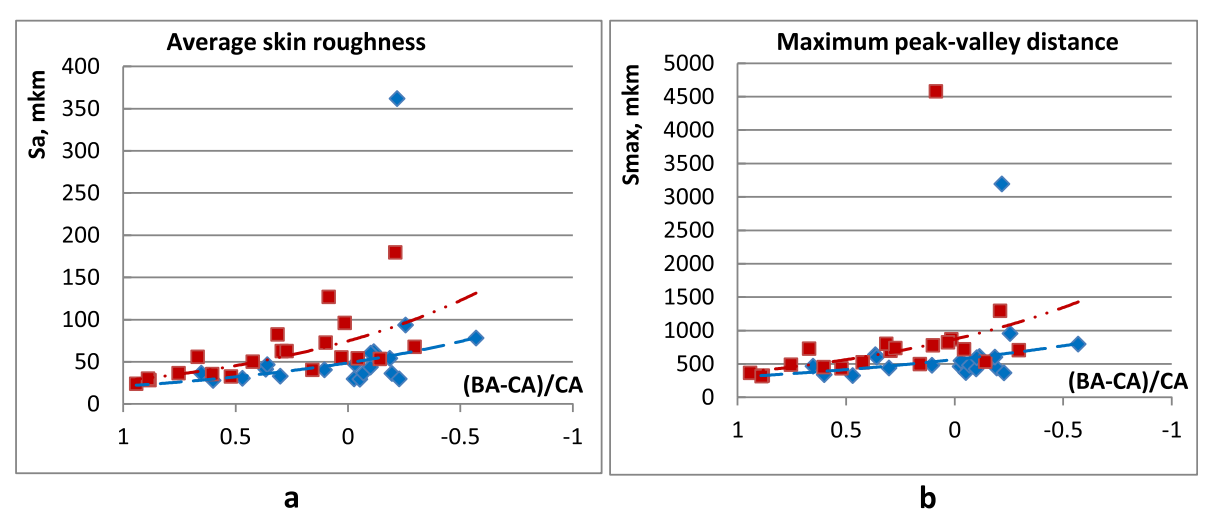

Fig. 6 Average skin roughness $\mathrm{Sa}(\mathbf{a})$ and maximum stretching of the roughness profile difference between the highest "peak" and the deepest "valley" within the whole measured area) Smax (b) for all participants. In the corresponding trend lines, best fit is given by exponential curves (see Table 1). Note that positive normalized age difference (BA - CA)/CA corresponds to young, negative difference to elderly participants 
Table 1 Trend lines for the dependencies of skin roughness parameters on the age difference $(x=B A-C A)$ for male and female participants

\begin{tabular}{lllllll}
\hline & Sa & Smax & $S z$ & $S p$ & Sv & \multicolumn{1}{c}{ Sda } \\
\hline Female & $y=48.80 \mathrm{e}^{-0.83 x}$, & $y=565.2 \mathrm{e}^{-0.62 x}$, & $y=725.9 \mathrm{e}^{-0.83 x}$, & $y=237.5 \mathrm{e}^{-0.29 x}$, & $y=282.3 \mathrm{e}^{-0.57 x}$, & $y=0.181 \mathrm{e}^{-0.43 x}$, \\
& $R^{2}=0.209$ & $R^{2}=0.160$ & $R^{2}=0.384$ & $R^{2}=0.060$ & $R^{2}=0.209$ & $R^{2}=0.377$ \\
Male & $y=74.69 \mathrm{e}^{-0.99 x}$, & $y=74.69 \mathrm{e}^{-0.99 x}$, & $y=494.6 \mathrm{e}^{-0.60 x}$, & $y=321.4 \mathrm{e}^{-0.45 x}$, & $y=371.4 \mathrm{e}^{-0.76 x}$, & $y=0.255 \mathrm{e}^{-0.42 x}$, \\
& $R^{2}=0.555$ & $R^{2}=0.555$ & $R^{2}=0.134$ & $R^{2}=0.314$ & $R^{2}=0.388$ & $R^{2}=0.395$ \\
\hline
\end{tabular}

around CA about 35 years for female and about 45 years for male participants recovered from the blood immunology and dermal and epidermis cell profile (Martínez de Toda et al. 2016) are showing very good correspondence. Such difference can be attributed to the impact of the estrogens assumed suppressors of innate immunity (Csaba 2019). For some of the blood immunity status indicators, scatter of the values are also quite high, but for many of them trend changes in the dependences on the age difference BA - CA are still pronounced and appear close to the values $\mathrm{BA}=\mathrm{CA}$.

Certain general observations can also be made from the data acquired for the roughness parameters of the skin. Firstly, there are no specific trend line anomalies in the data, skin roughness parameters of all participants (either male or female) increase with the age, including the plots against the age difference $(\mathrm{BA}-\mathrm{CA})$, or normalized age difference (both (BA - CA)/CA and (BA $\mathrm{CA} / \mathrm{BA}$ ). In addition, male skin tends to be rougher than that of females one more or less for all age. Thirdly, in the "early age" group the individual differences of the skin roughness parameters between participants are not very significant. Near and above "critical age" $(\mathrm{BA}=\mathrm{CA})$ such individual skin roughness differences are becoming significant and, in some cases, extreme and continuously increase with changing BA - CA (Fig. 7). Individual differences in the male skin roughness are also much more pronounced. These observations can be used to support formulated hypothesis that "critical age point" may present certain watershed between young and aging skin helping to individualize the decisions on corresponding skin treatment.

It should be stressed that average roughness parameters (like the ones given by Cutometer measurements) may be not optimal for describing surface roughness features for any specific surface, biological or technological alike, as it was shown in relation to the discussion on "optimum roughness" of metallic biomedical implants (e.g., Albrektsson and Wennerberg 2004; Löberg et al. 2010; Koptyug et al. 2014). For example, average parameters cannot adequately distinguish between surfaces with intense waviness (with large characteristic dimensions of features on the surface) having small or large micro-roughness (small scale features on the top), as average roughness values will be still dominated by the waviness (Koptyug et al. 2014). And it is suggested that data of actual measured surface profiles should be analyzed using spectral methods, reflecting the "density" of the features having certain dimensions. In technology, modern instruments allow for embedded functionality providing such analysis. However, in many situations, corresponding analysis of the surface profiles ("raw

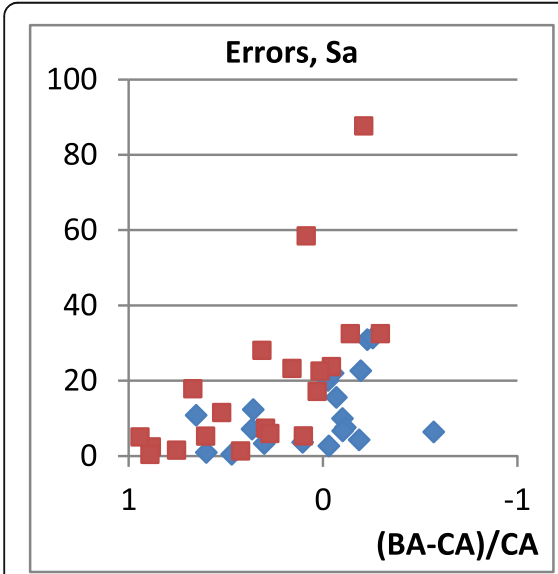

a

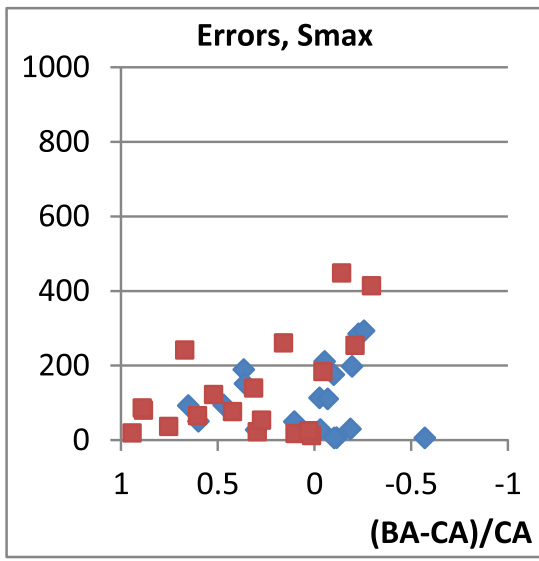

b

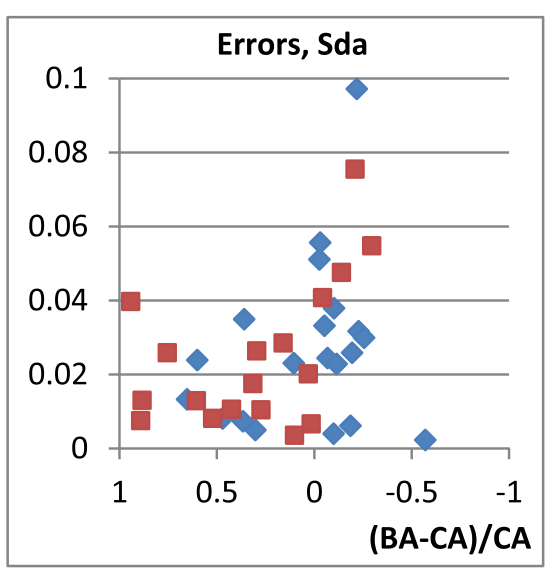

C

Fig. 7 Dependencies of the absolute values for the difference between measured values and trend lines (Table 1) for the skin roughness parameters Sa (a), Smax (b), and Sda (c). Values in micrometers, red squares—male participants, blue diamonds—female participants. Note that positive values of the normalized age difference correspond to young age 
profile data") are used for the following post-processing. In case of skin roughness characterization, such approach may also be better than using averaged roughness parameters, but as far as we are aware, commercial measurement units like Cutometer do not have the option of providing raw data from the roughness profiles.

\section{Correlation analysis}

Even without true correlation analysis, it could be observed that for many measured parameters trends in the dependencies for the blood immunology and skin cell profiles have certain special points at the same or very similar age difference values. Figure 8 illustrates this statement for the dependencies on the normalized age difference (BA - CA)/BA of the percentages of blood and skin Ts lymphocytes (a) and Th lymphocytes (b) for male participants. It is also quite clear that special point position for male in these graphs is some shifted from $\mathrm{BA}=\mathrm{CA}$ towards younger age.

With all reservations due to the relatively small number of participants in the studies, basic correlation analysis of all acquired data can be useful. Pearson correlation analysis was carried out between the roughness parameters of the skin and other measured parameters for all participants (including the results discussed in Sukhovei et al. 2019). Largest correlation coefficients between the skin roughness parameters and age difference (BA - CA) were found for two of them, namely average skin roughness, $\mathrm{Sa}$, and depth of the deepest profile valley, Sv (Table 2). Certain correlations between other skin roughness parameters and age difference BA - CA are also present.

Tables 3 and 4 present the correlations of two roughness parameters $S a$ and $S v$ and skin cell and immune status parameters (see Sukhovei et al. 2019; for corresponding discussions and data analysis for the skin cell profile parameters). Corresponding correlations of the chosen skin roughness parameters $(S a$ and $S v)$ with the epidermal cell counts are rather significant on all positions (except for endotheliocytes and activated endotheliocytes II). Correlations with the skin immune parameters also exist, but on smaller number of positions as compared to the epidermal cell counts. It is not surprising taking into account that skin status and topography was measured on the face, skin cell status was assessed using the samples taken from the gluteal region, and the immunology status is assessed using venous blood samples.

Characteristically, in cases of significant correlations, corresponding coefficients with $S v$ are positive and with $\mathrm{Sa}$ negative. It actually seems counterintuitive, as deeper valleys (reflected by larger $S v$ values) usually mean larger surface roughness (e.g., larger $S a$ values). Reflecting to the above discussion on the impact of extracting only averaged parameters from actual skin topography profiles, this may mean that deep skin features with small width (wrinkles) should be analyzed separately and may give better indication of skin aging.

Correlations of the age difference and parameters representing epidermal cell profile (Table 5) and skin immune profile discussed in (Sukhovei et al. 2019) were also calculated (Table 6). Correlations of the age difference parameter (BA - CA) are equally significant for the same epidermal cell count parameters, as it is for the correlations of skin roughness ones. Again, there is negligible correlation with the overall number of endotheliocytes, but there is a strong correlation with the number of activated endotheliocytes II. Skin immune profile parameters also show certain correlations with age difference, with strongest correlations for epidermal $\mathrm{T}$ lymphocyte, Th lymphocyte, and B lymphocyte numbers.

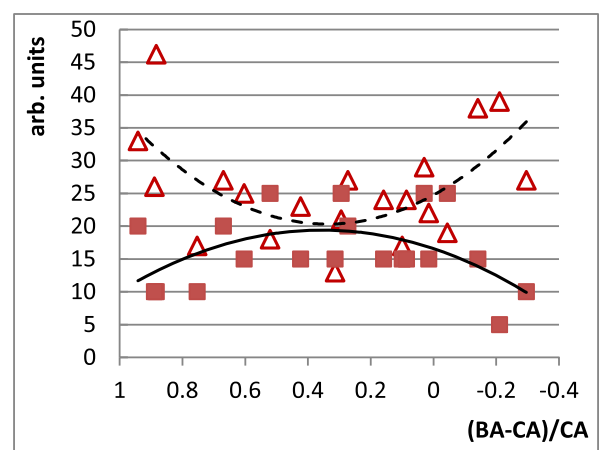

a

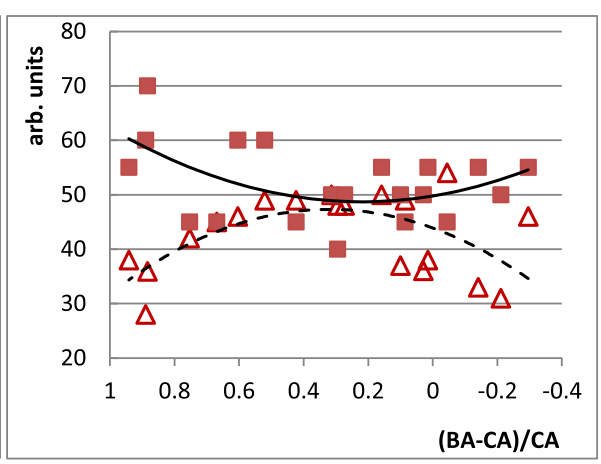

b

Fig. 8 Visual illustration of blood and skin cell profile parameter correlations: a numbers of cytotoxic Ts lymphocytes in blood (triangles) and epidermis (squares); b numbers of Th lymphocytes in blood (triangles) and epidermis (squares) for male participants plotted against normalized age difference (BA - CA)/CA, with corresponding second order polynomial fitting curves. To help visualization blood lymphocyte relative numbers are unchanged, but all values for the skin lymphocytes are multiplied by 5 . Original values are in percentage to the overall $\mathrm{T}$ cell counts. Note that positive age difference corresponds to the young age 
Table 2 Correlation between skin roughness parameters and age difference $B A-C A$

\begin{tabular}{lc}
\hline $\begin{array}{l}\text { Skin roughness parameter (calculated by the Cutometer } \\
\text { embedded software) }\end{array}$ & BA - CA \\
\hline $\begin{array}{l}\text { Sa, average roughness } \\
\text { Smax, maximum stretching of the roughness }\end{array}$ & $-0.381^{*}$ \\
$\begin{array}{l}\text { profile (difference between the highest "peak" } \\
\text { and the deepest "valley" within the whole }\end{array}$ & -0.194 \\
measured area) & \\
Sz, ten-point height (average value of 5 highest & -0.278 \\
peaks minus average value of 5 deepest valleys & \\
within the whole measured area) & -0.268 \\
$S p$, height of the greatest profile peak & $0.413^{* *}$ \\
$S v$, depth of the deepest profile valley & -0.269 \\
$S d a$, mean dale area (average value of the local & \\
profile slope in the measured plane) & \\
${ }^{*} p<0.05$; ${ }^{*} p<0.01$ &
\end{tabular}

To complete the analysis, correlations of the skin roughness parameters $(S a$ and $S v)$ as well as the correlations of the age difference parameter (BA - CA) with the blood cell counts and blood immune profile were calculated. In the majority of cases, correlations were found to be small or insignificant. The only blood immunity parameters having correlation coefficients with $S a$ and $S v$ above 0.2 are:

- Immunoglobulins IgM, IgG, and IgE

- Parameters of monocyte tests (stimulated and spontaneous NBT test; numbers of monocytes attached to the membrane surface of opsonized sheep erythrocytes)

- Numbers of T lymphocytes and B lymphocytes

- Amount of soluble immune complexes in the tests using precipitation by $7 \%$ polyethylene glycol

Largest correlation coefficients in this case were for the numbers of B lymphocytes: -0.385 with $S v(p<$ $0.05)$ and +0.278 with $S a$. Similarly, the only blood immune parameters having correlation coefficients

Table 3 Correlations between two average skin roughness parameters and skin cell numbers

\begin{tabular}{lll}
\hline Skin cells & Sa & Sv \\
\hline Keratinocytes & $-0.617^{* *}$ & $+0.689^{* *}$ \\
Activated keratinocytes & $-0.421^{* *}$ & $+0.449^{* *}$ \\
Fibroblasts & $-0.559^{* *}$ & $+0.664^{* *}$ \\
Activated fibroblasts & $-0.446^{* *}$ & $+0.533^{* *}$ \\
Endotheliocytes & -0.053 & -0.005 \\
Activated endotheliocytes (I) & $-0.421^{* *}$ & $+0.565^{* *}$ \\
Activated endotheliocytes (II) & -0.222 & +0.290 \\
Activated endotheliocytes (II) & $-0.419^{* *}$ & $+0.568^{* *}$ \\
\hline
\end{tabular}

${ }^{* *} p<0.01$
Table 4 Correlations between two average skin roughness parameters and skin immune status parameters

\begin{tabular}{lll}
\hline Skin immune status & Sa & SV \\
\hline Mastocytes & +0.165 & -0.111 \\
Activated mastocytes & +0.206 & +0.065 \\
Monocytes & $-0.407^{*}$ & $+0.461^{* *}$ \\
Activated monocytes & -0.282 & $+0.333^{*}$ \\
T lymphocytes & $-0.549^{* *}$ & $+0.484^{* *}$ \\
Th lymphocytes & $-0.445^{* *}$ & +0.314 \\
Ts lymphocytes & -0.123 & +0.242 \\
B lymphocytes & $-0.359^{*}$ & $+0.449^{* *}$ \\
NK cells & -0.282 & $+0.422^{* *}$ \\
${ }^{*} p<0.05 ;{ }^{* *} p<0.01$ & &
\end{tabular}

with (BA - CA) above 0.2 are immunoglobulins IgM $(-0.243)$ and $\operatorname{IgE}(0.642, p<0.01)$, parameters of monocyte tests (stimulated and spontaneous NBT test, -0.398 and $-0.353, p<0.05$ ) and number of $\mathrm{T}$ lymphocytes $(-0.279)$, and amount of soluble immune complexes in the tests using precipitation by $7 \%$ polyethylene glycol (0.463).

Analysis of the parameter correlations supports the suggestion that dermal and epidermal cell profile, immune profile, and skin topography are inter-related (for some combinations clearly correlated) and that individual parameters (BA - CA) has a strong potential of reflecting skin vitality and state linked to its aging. At the same time, blood immunity indicators are not that strongly correlated to the skin parameters such as skin roughness, or to the age difference parameter (BA - CA). At the same time, certain links of the blood immunity profile to the skin state and age difference seems to exist.

\section{Summary of the data analysis}

Analysis of the epidermal cell profile, skin immune profile, and skin roughness parameter changes with age shows peculiarities in their dependence on the difference of the chronologic and calculated biologic age. Young individuals have biologic age larger than the chronologic, and in later life, it becomes smaller then chronologic one (if the biologic age is calculated using chosen expressions 1 and 2, and the boundaries of the "early," "critical," and "later age" are defined according to expression 3). It appears that dependencies of the critical parameters assumed to be relevant and reflecting skin aging process are changing trends, or having their maximum or minimum near the crossover point $\mathrm{BA}=\mathrm{CA}$ (calculated biologic age is equal to the chronologic one). Skin roughness increases much more intensely for the late age $(\mathrm{BA}<\mathrm{CA})$, and parameter differences between individuals are becoming much more significant. Trend lines for the skin parameter dependencies for male and 
Table 5 Correlation between epidermal cell profile parameters and age difference BA - CA

\begin{tabular}{ll}
\hline Epidermal cell numbers & BA - CA \\
\hline Keratinocytes & $0.671^{* *}$ \\
Activated keratinocytes & $0.444^{* *}$ \\
Fibroblasts & $0.69^{* *}$ \\
Activated fibroblasts & $0.539^{* *}$ \\
Endotheliocytes & 0.007 \\
Activated endotheliocytes (I) & $0.597^{* *}$ \\
Activated endotheliocytes (II) & $0.405^{*}$ \\
Activated endotheliocytes (II) & $0.532^{* *}$ \\
\hline
\end{tabular}

${ }^{* *} p<0.01 ;{ }^{*} p<0.05$

female also tend to crossover near the point $\mathrm{BA}=\mathrm{CA}$. Analysis of the blood cell profile and immune status shows similar peculiarities in the dependences on (BA - CA), though in many cases they are less pronounced than that for the ones reflecting skin roughness. There are certain correlations between BA - CA and skin roughness parameters, but much more pronounced are the correlations with epidermal cell profile and immune status parameters. The "crossover point" BA = CA is different for male and female participants (see also the results presented in Gruenewald et al. 2006; Klemera and Doubal 2006; Fahy et al. 2019), differing almost 10 years being about 35 years for female and 45 years for male participants.

\section{Conclusions}

In line with findings from other authors and following the results of present studies, one can conclude that the difference of calculated biologic and chronologic age may indeed be used as an indicator of significant changes related to aging, and in particular, the changes in skin properties including epidermal cell and immunity profiles underlying the skin aging processes. This

Table 6 Correlation between skin immune profile parameters and age difference BA - CA

\begin{tabular}{ll}
\hline Epidermal immune cell numbers & BA - CA \\
\hline Mastocytes & 0.118 \\
Activated mastocytes & 0.173 \\
Monocytes & 0.212 \\
Activated monocytes & 0.258 \\
T lymphocytes & $0.577^{* *}$ \\
Th lymphocytes & $0.486^{* *}$ \\
Ts lymphocytes & 0.015 \\
B lymphocytes & $0.457^{* *}$ \\
NK cells & 0.258 \\
\hline
\end{tabular}

${ }^{* *} p<0.01$ conclusion is well supported by the studies of the age dynamics of skin cell profile parameters, skin and blood immunology profile, skin moisture and sebum levels, and skin roughness values. The dependence of the skin roughness parameters on the biologic and chronologic age difference shows clear increase of the skin roughness for the late age (as defined by used expressions), together with significantly increasing individual differences. It also is clear that for better individualization expressions for calculating biologic age for male and female could be further adjusted. Thus, it can be concluded that available experimental data support the hypothesis that a difference of the biologic age, calculated basing on the forced vital lung capacity value, systolic blood pressure, urea concentration in urine and blood cholesterol level, and a chronologic age could be used as an individual express criterion supporting the decisions on the need and intensity of the skin treatment. Analysis of the results also indicates that it is possible to qualify the skin status according to the early age, critical age, and late age concept with the critical age boundary defined as $|\mathrm{BA}-\mathrm{CA}|<5$ years. It is also suggested that using this criterion can support the decisions if a person "does not need skin treatment," "may need certain, mild treatment," and "may need more intense skin care or treatment" depending on the particular clinical case. For the particular group of subjects, it was possible to redefine this criterion, linking it to the chronologic age of participants. Taking into account relative simplicity and generally good availability of the tests needed to acquire data for calculating biologic age using chosen expressions, such criterion can become a useful tool for skin care specialists and medics in taking decisions about skin care and skin treatment in individual cases.

Relatively small number of participants to certain extent restricts the validity of above conclusions, and thorough tests should be further performed with larger number of participants. It would also be important to perform a study following the same individuals for a period of time and correlating calculated biologic age with parameters related to aging and critical for taking decisions about skin treatment. It should be specifically noted that used expressions common for the geriatric research in Russia give counterintuitive values for biologic age (in this case, biologic age is larger than chronologic one for young people). In addition, additional studies should be performed to analyze if the other accepted expressions for the biologic age calculation would be equally good or better when predictors of the critical to skin aging are based on the age difference BA - CA.

\section{Abbreviations}

BA: Biologic age; BC: Blood cholesterol level; CA: Chronologic age; FVC: Forced vital lung capacity; NBT: Nitro-blue tetrazolium; PEG: polyethyleneglycol; Sa: Average roughness; SBP: Systolic blood pressure; 
Sda: Arithmetic mean of the profile slope of the roughness profile; Smax: Maximum stretching of the roughness profile; Sp: Height of the greatest profile peak; Sv: Depth of the deepest profile valley; Sz: Average value of five highest peaks minus average value of five deepest valleys; UC: Urea concentration in urine

\section{Acknowledgements}

Authors express their acknowledgements to Professor Vladimir Kozlov from the Institute of Clinical and Experimental Immunology for fruitful discussions.

\section{Authors' contributions}

Main idea of the research belongs to YS; authors of the main hypothesis were YS and AK; designing, organizing, and performing experiments were done by YS, EK, IU, and DK; data analysis was performed by AK. All authors read and approved the final manuscript.

\section{Funding}

Studies were carried out within the current research program of the Institute of Clinical Immunology and no external funding was received.

\section{Availability of data and materials}

The data supporting findings of this study are available from the Institute of Clinical and Experimental Immunology. Certain restrictions apply to the availability of the data used under license covering present study, and so some of the data are not publically available. Data are however available from the authors upon request and with permission from the Institute of Clinical and Experimental Immunology.

\section{Ethics approval and consent to participate}

All participants were properly informed on the nature of studies and specific procedures and gave signed written consent to participate. The consent forms and the plans for the research were approved by the Ethics Commission of the Institute of Clinical Immunology according to the formal requirements issued by the State Department of Health of Russian Federation.

\section{Consent for publication}

All participants and authors gave their consent for the publication of the study results, and a formal consent for publication was granted by the Research Council of the Institute of Clinical and Experimental Immunology. It is also confirmed that the work conforms to the principles of WHO Helsinki Declaration.

\section{Competing interests}

The authors declare that they have no competing interests.

\section{Author details}

${ }^{1}$ Institute of Clinical Immunology, Tyumen branch, Kotovskogo str., 5 , Tyumen, Russia. ${ }^{2}$ Mid Sweden University, SportsTech Research Centre, Akademigatan 1, Östersund, Sweden.

Received: 15 June 2019 Accepted: 14 November 2019

\section{Published online: 14 January 2020}

\section{References}

Albrektsson T, Wennerberg A. Oral implant surfaces: part 1-review focusing on topographic and chemical properties of different surfaces and in vivo responses to them. Int J Prosthodont. 2004;17:536-543.PMID: 15543911.

Alonso-Fernández $\mathrm{P}$, de la Fuente $\mathrm{M}$. Role of immune system in aging and longevity. Current Aging Science. 2011;4:78-100. PMID: 21235494.

Arce-Lopera C, Igarashi T, Nakao K, Okajima K. Image statistics on the age perception of human skin. Skin Res Technol. 2013;19:e273-8. https://doi.org/ 10.1111/j.1600-0846.2012.00638.x.

Beloserova LM. Algorythm for designing biologic age calculation expressions. Esthetic Medicine (Эстетическая Медицина, paperin Russian). 2006;5: 199-204.

Belsky DW, Caspi A, Houts R, Cohen HJ, Corcoran DL, Danese A, et al. Quantification of biological aging in young adults. Proc Natl Acad Sci USA. 2015. https://doi.org/10.1073/pnas.1506264112.

Belsky DW, Huffman KM, Pieper CF, Shalev I, Kraus WE. Change in the rate of biological aging in response to caloric restriction: CALERIE Biobank
Analysis. J Gerontol A Biol Sci Med Sci. 2017;73:4-10. https://doi.org/10. 1093/gerona/glx096.

Benjamin H. Biologic versus chronologic age. J Gerontol. 1947;2:217-27. https:// doi.org/10.1093/geronj/2.3.217.

Bhomick PC, Rao KS. Toxic shades- chemicals in cosmetics that matters. Journal of Applicable Chemistry. 2014;3:436-9 ISSN: 2278-1862.

Borkan GA, Norris AH. Assessment of biological age using a profile of physical parameters. J Gerontol. 1980;35:177-84. https://doi.org/10.1093/ geronj/35.2.177.

Castelo-Branco C, Soveral I. The immune system and aging: a review. Gynecological Endocrinology. 2014;30:16-22. https://doi.org/10.3109/ 09513590.2013 .852531$.

Chia D, Barnett EV, Yamagata J, Knutson D, Restivo C, Furst D. Quantitation and characterization of soluble immune complexes precipitated from sera by polyethylene glycol (PEG). Clin Exp Immunol. 1979;37:399-407. PMID: 315842.

Coltman CE, Steele JR, McGhee DE. Effect of aging on breast skin thickness and elasticity: implications for breast support. Skin Res Technol. 2017;23:303-11. https://doi.org/10.1111/srt.12335.

Csaba G. Immunity and longevity. Acta Microbiolica et Immunologica Hungarica. 2019;66:1-17. https://doi.org/10.1556/030.65.2018.029.

Dean W. Biological aging measurement - clinical applications. Center for Bio Gerontology, Los Angeles. 1986;ISBN-13:978-0937777008.

Dean W. Biological aging measurement. Arch Gerontol Geriatr. 1998;1:64-85. PMID: 3052338

Fahy GM, Brooke RT, Watson JP, Good Z, Vasanawala SS, Maecker H, Leipold MD, Lin DTS, Kobor MS, Horwath S. Reversal of epigenetic aging and immunosenescent trends in humans. Aging Cells. 2019. https://doi.org/10.1111/acel.13028.

Freeman R, King B. Technique for the performance of the nitro-blue tetrazolium (NBT) test. J Clin Pathol. 1972;25:912-4. https://doi.org/10.1136/jcp.25.10.912.

Freis O, Perie G. RathjensA. Correlating aging with skin's mechanical and optical properties. Cosmetics \& Toiletries. 2014;129:66-75.

Giaimis J, Lombard Y, Makaya-Kumba M, Fonteneau P, Poindron P. A new and simple method for studying the binding and ingestion steps in the phagocytosis of yeasts. J Immunol Method. 1992;154:185-93. https://doi.org/ 10.1016/0022-1759(92)90191-u.

Gilchrest BA. Skin aging 2003: recent advances and current concepts. Cutis. 2003; 72:5-10; discussion 10 PMID: 14533824

Gordon AM, Rowan RM, Brown T, Carson HG. Routine application of the nitroblue tetrazolium test in the clinical laboratory. J Clin Pathol. 1973;26:526. https://doi.org/10.1136/jcp.26.1.52.

Gruenewald TL, Seeman TE, Ryff CD, Karlamangla AS, Singer BH. Combinations of biomarkers predictive of later life mortality. Proc Natl Acad Sci USA. 2006;103: 14158-63. https://doi.org/10.1073/pnas.0606215103.

Gupta MA, Gilchrest BA. Psychosocial aspects of aging skin. Dermatol Clin. 2005; 23:643-8. https://doi.org/10.1016/j.det.2005.05.012.

Gupta MA, Gupta AK. Psychological impact of aging and the skin. In: Koo JYM, Lee CS, editors. Psychocutaneous medicine. Marcel Dekker: New York; 2003. p. 365-73. https://doi.org/10.1201/9780203911877.

Hart PH, Grimbaldeston MA, Hosszu EK, Swift GJ, Noonan FP, Finlay-Jones J. Age-related changes in dermal mast cell prevalence in BALB/c mice: functional importance and correlation with dermal mast cell expression of Kit. Immunology. 1999;98:352-6. https://doi.org/10.1046/j.1365-2567. 1999.00897.x.

Jacobi U, Chen M, Frankowski G, Sinkgraven R, Hund M, Rzany B, et al. In vivo determination of skin surface topography using an optical $3 \mathrm{D}$ device. Skin Res Technol. 2004;10:207-14. https://doi.org/10.1111/j.16000846.2004.00075.x.

Kang YG, Suh E, Chun H, Kim SH, Kim DK, Bae CY1. Models for estimating the metabolic syndrome biological age as the new index for evaluation and management of metabolic syndrome. Clin Interv Aging. 2017;12:253-261. https://doi.org/10.2147/CIA.S123316

Kazanci A, Kurus M, Atasever A. Analyses of changes on skin by aging. Skin Res Technol. 2017;23:48-60. https://doi.org/10.1111/srt.12300.

Kiecolt-Glaser JK, Preacher KJ, MacCallum RC, Atkinson C, Malarkey WB, Glaser R. Chronic stress and age-related increases in the proinflammatory cytokine IL6. Proc Natl Acad Sci U S A. 2003;100:9090-5. https://doi.org/10.1073/pnas. 1531903100 .

Klemera P, Doubal S. A new approach to the concept and computation of biological age. Mech Agng Dev. 2006;127:240-8. https://doi.org/10.1016/j. mad.2005.10.004 
Koblenzer CS. Psychologic aspects of aging and the skin. Clin Dermatol. 1996;14: 171-7. https://doi.org/10.1016/j.clindermatol.2003.11.010.

Konduracka E, Krzemieniecki K, Gajos G. Relationship between everyday use cosmetics and female breast cancer. Pol Arch Med Wewn. 2014; 124:264-269. PMID: 24694726.

Koptyug A, Rännar L-E, Bäckström M. Multiscale surface structuring of the biomedical implants manufactured in electron beam melting technology: demands, advances and challenges. Proc. iCAT-2014, International Conference on Additive Technologies, Vienna, Austria, 15 - 17 October 2014, Igor Drstvenšek, Editor, 2014.

Kwon YH, da Vitoria Lobo N. Age classification from facial images. Computer Vision and Image Understanding. 1999;74:1-21. https://doi.org/10.1006/cviu.1997.0549.

Löberg J, Mattisson I, Hansson S, Ahlberg E. Characterisation of titanium dental implants i: critical assessment of surface roughness parameters. The Open Biomaterials Journal. 2010;2:18-35. https://doi.org/10.2174/ 1876502501002010018

Mann ER, Smith KM, Bernardo D, Al-Hassi HO, Knight SC. Hart AL. Review: skin and the immune system., J Clin Exp Dermatol. 2012. https://doi.org/10.4172/ 2155-9554.S2-003.

Martínez de Toda I, Maté I, Vida C, Cruces J, De la Fuente M. Immune function parameters as markers of biological age and predictors of longevity. Aging. 2016;8:3110-9. https://doi.org/10.18632/aging.101116.

Masuda Y, Oguri M, Morinaga T, Hirao T. Three-dimensional morphological characterization of the skin surface micro-topography using a skin replica and changes with age. Skin Res Technol. 2014;20:299-306. https://doi.org/10. $1111 /$ srt.12119.

Matts PJ. New insights into skin appearance and measurement. Journal of Investigative Dermatology Symposium Proceedings. 2008;13:6-9. https://doi. org/10.1038/jidsymp.2008.6

Mosser DM, Zhang X. Measuring opsonic phagocytosis via Fcy receptors and complement receptors on macrophages. Curr Protoc Immunol. 2011; Chapter 14:Unit 14.27. https://doi.org/10.1002/0471142735.im1427s95

Müller J, Alföldy P, Lemmel EM. Nitroblue-tetrazolium test for the functional evaluation of phagocytic cells: a critical analysis of the methodology. Agents Actions. 1981;11:384-90. https://doi.org/10.1007/bf01982475.

Naylor EC, Watson RE, Sherratt MJ. Molecular aspects of skin ageing. Maturitas. 2011;69(3):249-56. https://doi.org/10.1016/j.maturitas.2011.04.011.

Nedelec B, Forget NJ, Hurtubise T, Cimino S, de Muszka F, Legault A, et al. Skin characteristics: normative data for elasticity, erythema, melanin, and thickness at 16 different anatomical locations. Skin Res Technol. 2016;22:263-75. https://doi.org/10.1111/srt.12256.

Ohlson S, Zetterstrand K. Detection of circulating immune complexes by PEG precipitation combined with ELISA. J Immunol Methods. 1985;77:87-93. https://doi.org/10.1016/0022-1759(85)90186-3.

Porcheron A, Mauger E, Russell R. Aspects of facial contrast decrease with age and are cues for age perception. PLoS One. 2013;8:e57985. https://doi.org/10 1371/journal.pone.0057985.

Shetage SS, Traynor MJ, Brown MB, Raji M, Graham-Kalio D, Chilcott RP. Effect of ethnicity, gender and age on the amount and composition of residual skin surface components derived from sebum, sweat and epidermal lipids. Skin Res Technol. 2014;20:97-107. https://doi.org/10.1111/srt.12091.

Sukhovei Y, Kostolomova E, Unger I, Koptyug A, Kaigorodov D. Difference between the biologic and chronologic age as an individualized indicator for the skincare intensity selection: skin cell profile and age difference studies. BMC Dermatol. 2019;9:10. https://doi.org/10.1186/s41702-019-0051-1.

Trojahn C, Dobos G, Schario M, Ludriksone L, Blume-Peytavi U, Kottner J. Relation between skin micro-topography, roughness, and skin age. Skin Res Technol. 2015;21:69-75. https://doi.org/10.1111/srt.12158.

Voitenko VP, Tokar AV. The assessment of biological age and sex differences of human aging. Exp Aging Res. 1983;9:239-44. https://doi. org/10.1080/03610738308258458.

Waters J. Cosmetics and the job market. In: Graham JA, Kligman AM, Editors. The psychology of cosmetic treatments. Praeger, New York; 1986: 113-124. ISBN13: 978-0317046519.

Webster IW, Logie AR. A relationship between functional age and health status in female subjects. J Gerontol. 1976;31:546-50. https://doi.org/10.1093/geronj/ 31.5.546.

Woo MS, Moon KJ, Jung HY, Park SR, Moon TK, Kim NS, et al. Comparison of skin elasticity test results from the Ballistometer $\left(^{\oplus}\right)$ and Cutometer $\left({ }^{(}\right)$. Skin Res Technol. 2014;20:422-8. https://doi.org/10.1111/srt.12134.
World Medical Association. World Medical Association Declaration of Helsinki. Ethical Principles for Medical Research Involving Human Subjects. JAMA. 2013;310:2191-4. https://doi.org/10.1001/jama.2013.281053.

Zhang S, Duan E. Fighting against skin aging: the way from bench to bedside. Cell Transplant. 2018;27:729-38. https://doi.org/10.1177/0963689717725755.

\section{Publisher's Note}

Springer Nature remains neutral with regard to jurisdictional claims in published maps and institutional affiliations.
Ready to submit your research? Choose BMC and benefit from:

- fast, convenient online submission

- thorough peer review by experienced researchers in your field

- rapid publication on acceptance

- support for research data, including large and complex data types

- gold Open Access which fosters wider collaboration and increased citations

- maximum visibility for your research: over $100 \mathrm{M}$ website views per year

At BMC, research is always in progress.

Learn more biomedcentral.com/submissions 